\title{
Transitioning to a New Normal: How Ecopsychology Can Help Society Prepare for the Harder Times Ahead
}

\section{Raymond De Young}

\section{School of Natural Resources and Environment, University of Michigan, Ann Arbor, Michigan.}

Not in his goals but in his transitions is man great. -Ralph Waldo Emerson (1870 Harvard lecture)

\section{A New Context}

$\mathrm{H}$ owever vast were the resources used to create industrial civilization, they were never limitless. Biophysical constraints, always a part of human existence, could be ignored for these past few centuries, a one-time era of resource abundance. This is no longer possible.

Many of the challenges we face can be traced to our centurieslong consumption and construction binge and, soon, to its abrupt culmination. Climate disruption, a consequence of our rapacious use of fossil fuels, is intensifying. The amount of available net energy (the energy available to society after deducting energy used during extraction and production) was massive at first, misleading us with the false prospect of endless growth. False because, easily unnoticed, net energy has been on a relentless decline. We are approaching the day when net energy becomes insufficient for maintaining, let alone building out, modern society. Technological innovation, to which we attribute much of our success, cannot create energy or natural resources, and our industrial prowess cannot negate the laws of thermodynamics. Thus, while our ingenuity can slow the approach of a resource-limited future, it will not fundamentally change that outcome.

Soon we will leave behind the infantile techno-fantasy of a world without limits giving us a life without want. We will all, of necessity, accept that biophysical limits are a defining characteristic of life.
Such acceptance is long overdue but hard for us, hard because it demands profoundly different worldviews and patterns of living. Ecopsychology can help us realize that our future will be attained through thrift and humility, not by the consumptive growth and boosterism that gave us our fling with material affluence. Unfortunately, we may well try all possible alternatives to outright acceptance before realizing that limits are, by their very nature, not open to negotiation or repudiation.

Yet acceptance is but the first step and not nearly as hard as what comes next. The depth and duration of the required transition is unprecedented. Adapting well to a drawn-out decline in resource availability is not something with which we are familiar. Furthermore, since we seem to be starting late in the process, having temporarily delayed the needed behavior change, we will likely need to quickly respond to events. Prefiguring our response could ease the transition.

It is here that ecopsychology can play an essential role, since what is being faced is not a technological or political challenge but an existential one. The broader missions of ecopsychology and that of a society facing biophysical constraints will converge on the need to lay a new foundation for sustainable, interdependent, and mutually enhancing relations with nature as well as within the human community. In fact, the coming transition provides the ecopsychology community with a rare moment. During the initial phase of downshifting, there likely will be a period of flux, a time during which people might be willing to reshape their emotional connection and moral stance toward each other and the rest of the planet. It is during this time that our community's ongoing efforts to promote ecological consciousness and to help people reconnect with nature might turn to the even larger goal of adopting an ecological partnership society to replace the extractive dominator society. 


\section{DE YOUNG}

\section{Behavioral Simplification}

When growth was an easy thing to do, we found it possible to disregard the biophysical foundation of society. Later, as limits were first anticipated and then became apparent, some among us advocated for behavior change. Yet society cunningly avoided dramatic change in favor of a green technology and policy approach. We were sold on the belief that nature and natural capital could be sustained by "greening and leaning" industrial civilization. We could note that pursuing this approach for decades has produced no noticeable decline in our overall ecological footprint or emissions profile. Or we could point out that despite all effort at education and persuasion, consumerism continues to consume the planet. But the premise outlined above provides another prospect.

Soon, due to resource descent and/or declining net energy, society will be consuming less, ready or not. We will adopt a reduced-consumption pattern of living not because of extrinsic rewards or a global policy agreement or a planetwide emergence of ecological awareness but because we will have no other choice. We will consume less because there will be less to consume. Dire consequences will still arise from our past consumption (e.g., climate disruption), but future consumption will first slow then decline.

Dismal as this outlook sounds, it could help the transition. First, it is unlikely to happen all at once but instead emerge over decades-a persistent downshift to a new normal. This spares us from slipping into short-term emergency thinking where we imagine weathering the storm until the old normal returns. Second, no longer will we need to persuade people to change their lifestyle. No longer will the public need to judge the veracity of limits-to-growth arguments. Instead, a constraining biophysical reality will be unavoidable, directly perceivable and palpable. The need to downshift will be blatantly obvious. And the motivation for change will come from the interaction of biophysical reality and community self-interest.

Under this scenario, the process of societal transition will not await professional intervention, administrative permission, or venture capital support. It will start on its own, and as we say about revolutions, it will not be televised. But there is a great deal ecopsychology can do to help the transition and to learn from it.

No community of scholars is better prepared than we are to guide modern society through its reawakening to the effects of biophysical limits on everyday life. At a most basic level, people will grieve from losing an affluent lifestyle or from losing the belief that growth will one day provide such a future. If we do nothing else, it will be praiseworthy to help people respond well to this realization, to help them to cope better than they would otherwise. Ecopsychology's understanding of the therapeutic effect of interaction with nature may be put to good and frequent use.

But there is also a fascinating, if somewhat counterintuitive, aspect to a downshift. Life would become much less affluent, mobility more manual, and society more agrarian. Thus, slowly over time, the average daily access to nature may greatly increase. Ecopsychologists know that contact with nature is essential for humans to do well mentally, physically, and spiritually. But under the scenario outlined above, we will be presented with a unique opportunity, a chance to explore what long-term, society-wide, regular and intimate connection with the natural environment might achieve. Our understanding of and expectation about the effect are clear, but ecopsychology has never before had an example at this scope and duration to learn from.

\section{Pre-Familiarization}

Some people advocate quickening the process of simplification in order to leave surplus resources for the future. While a worthy goal, we must take care not to instill panic and chaos into the process. The transition must be done well the first time with the changes made durable; it is unlikely we will get a second chance.

Fortunately, there may be another way forward. Through a process of pre-familiarization, people can become mentally prepared for the leaner times ahead. This process is possible because the mind is about navigating the future, not just tracking the present. It turns out that a major barrier to changing behavior is not the inertia of the status quo but, rather, our desire for the familiar. Although this may sound as if it is a rather small, perhaps even an academic distinction, it is in fact a crucial issue, one with major implications for our role as counselors and educators.

A status quo bias means that very little will change, and what does change will change only in very small steps. A familiarity bias, in contrast, means that change is limited not by where people are but by what they know and where they imagine themselves going. The focus is on the insights and experiences that people have, not what their current circumstances happen to be. It is indeed fortunate that people can have knowledge that extends far beyond the comfortable outline of the status quo.

Since people are conceptual animals, what they can become familiar with is not limited to what they experience in a literal sense. People can acquire familiarity through experiences both direct and indirect: through the written word, artistic expression and simulations (e.g., plays); through observation at living museums, ecovillages, and farmer's markets; and through participation in reskilling fairs, workshops, and personal projects. 
Any affirmative examples we can provide of living well while living lightly could incubate pre-familiarization with a future far less affluent. Ecopsychology's leadership here would be in providing the imagery and richness of context necessary for people to deeply know the not-yet-present, thus helping them to feel at home in the lean times soon to be, but not yet, inhabited.

\section{Embedded Benefits}

A common prognosis by those accepting the premise of resource downshift is doom and gloom. Popular authors write books with apocalyptic titles, while respected environmentalists foretell a massive culling of the population. Perhaps such work sells because the authors and audiences imagine that our only choice is between the current folk mythologies of growth or apocalypse.

Ecopsychology practitioners do not believe in spreading fear or causing pain. Nonetheless, we may be ill advised to soothe the physical and social challenges of sustainable living. People have an innate inclination to act in ways that matter, to seek meaning in everyday activities. Thus, it may prove useful to validate the quiet, internal voice that finds satisfaction in life patterns that while hard are consequential.

There is no doubt that the coming transition will require much of us: new skills, resourcefulness and cooperation through stressful periods. Fortunately, humans find the related pursuits of competence, frugality, and participation to be intrinsically satisfying. Simply put, the very behaviors that need to be adopted contain their own rewards, perhaps because they are challenging, not despite that fact. Thus, instead of emphasizing the inevitability of the coming downshift, we might instead frame it as an opportunity containing hidden riches. So framed, people may pursue the simple life not because it is necessary but because it is important and fulfilling. Ordinary struggles may reveal extraordinary benefits.

The inevitability of biophysical limits does not predetermine a specific response. Society still has options, although it needs guidance. Ecopsychology has a role to play, but people will not wait for us to get ourselves focused. They may begin without us.

Our task, if we are willing to take it up, is to help people envision an alternative to the current relationship we have with resources. It is to help people to anticipate that everyday life will soon differ substantially from conventional expectations. Yet, as a result, to realize that psychological well-being likely will, if unexpectedly, improve.

Address correspondence to: Raymond De Young School of Natural Resources and Environment University of Michigan 440 Church Street Ann Arbor, MI 48109

E-mail: rdeyoung@umich.edu

Received: October 14, 2013

Accepted: November 5, 2013 